\title{
A Virtual Laboratory to support Chemical Reaction Engineering courses using real-life problems and industrial software
}

\author{
Juan Ramírez ${ }^{\mathrm{a}}$, David Soto ${ }^{\mathrm{a}}$, Sebastian Lopez ${ }^{\mathrm{a}}$, Jethro Akroyd ${ }^{\mathrm{b}}$, Daniel \\ Nurkowski $^{\mathrm{c}}$, Maria L. Botero ${ }^{\mathrm{b}}$, Nicola Bianco ${ }^{\mathrm{c}, *}$, George Brownbridge $^{\mathrm{c}}$, \\ Markus Kraft ${ }^{\mathrm{b}}$, Alejandro Molina ${ }^{\mathrm{a}, * *}$ \\ ${ }^{a}$ Bioprocesos y Flujos Reactivos, Facultad de Minas, Universidad Nacional de Colombia- \\ Sede Medellín, Carrera 80 \# 65-223 Medellín, Colombia \\ ${ }^{b}$ Computational Modelling (CoMo) Group, Department of Chemical Engineering and \\ Biotechnology (CEB), University of Cambridge, Philippa Fawcett Drive CB3 0AS, \\ Cambridge, United Kingdom \\ ${ }^{c}$ CMCL Innovations, Sheraton House, Castle Park, Cambridge CBз 0AX, Cambridge, \\ United Kingdom
}

\section{Abstract}

A virtual laboratory has been developed to support chemical reaction engineering courses. Real-life engineering challenges that are difficult to address in a university laboratory give the opportunity to illustrate basic concepts of chemical reaction engineering such as the relationship between temperature and reaction rate, space time and conversion, and inert concentration and selectivity. Six virtual experiments covering topics from petroleum refining, diesel combustion, nanoparticle growth, and hydrogen combustion form the basis of the virtual laboratory. The characteristics embedded in the experiments include the use of economic analysis to give closure to open-ended

\footnotetext{
*Currently at: Underwriter Laboratories, Compass House, Vision Park, Histon, Cambridge CB24 9BZ, Cambridge, United Kingdom

** Corresponding author

Email address: amolinao@unal.edu.co (Alejandro Molina)
} 
problems, the solution of engineering problems with high environmental relevance and finally, the ability to solve complex engineering problems related to state-of-the-art technologies, for example the synthesis of functionalized nanoparticles. Trial tests with senior students, with continual feedback and freedom in terms of the delivery date were used to evaluate and improve the experiments. Subsequently, a classroom test with 45 undergraduate students with a fixed deadline was performed. The challenges and opportunities to use virtual experiments supported by industrial software to teach real-life problems to undergraduate students have been critically assessed.

Keywords: virtual laboratory, industrial software, real-life problems, reaction engineering

\section{Introduction}

Most chemical engineering programs include graduate and undergraduate courses on reaction engineering. The literature related to chemical reaction engineering includes various textbooks (Ancheyta, 2017; Aris, 1999; Davis and Davis, 2013; Doraiswamy and Uner, 2013; Fogler, 2016; Froment et al., 2010; Holland and Anthony, 1979; Kramers and Westerterp, 1963; Levenspiel, 1962, 1999; Li et al., 2017; Marin and Yablonsky, 2011; Missen et al., 1999; Ranade, 2002; Schmal, 2014; Schmidt, 2009; Trambouze and Euzen, 2007; Walas, 2013), with different perspectives, that have contributed to the education of chemical engineers for the last seven decades. One characteristic that is recurrent in early textbooks is the predominance of $\mathrm{A}+\mathrm{B} \rightarrow \mathrm{C}$ type examples and monogram solutions, mainly due to the limited tools to perform complex calculations at the time when the textbooks were written. 
In recent years, textbooks have included more practical examples aided by state-of-the-art computational advances brought in by the personal computer revolution. In this way, problems that were too difficult to solve in the 1960s, became accessible to undergraduate students. Currently, there is now also the trend to use companion websites (Fogler and Gurmen, 2019; Froment et al., 2019; Levenspiel, 2019) to support textbooks.

At the same time different authors (Chen et al., 2016; Koretsky et al., 2008; Molderez and Fonseca, 2018; Naukkarinen and Sainio, 2018; Wolff et al., 2018) have documented the importance of solving real-life problems and using virtual environments to support the application of the theory learned in the classroom to professional challenges. Such real-life problems improve the ability to solve fully open-ended problems. The virtual and real-life character of a problem can be obtained via different strategies. For instance, while Koretsky et al. (2008) achieved a virtual character using a three-dimensional graphical interface that provided the look-and-feel of a typical semiconductor manufacturing environment from which students could perform reactor runs, take measurements, and obtain output data, Naukkarinen and Sainio (2018) employed a Moodle Discussion Feature where an instructor varied the conditions in a virtual reactor where a small set of coupled reactions took place in a homogeneous medium. Other approaches include exposure to industrial processes and professionals (Wolff et al., 2018), experiments where students were given the freedom to define the problem and the appropriate approach to find a solution (Chen et al., 2016), and the analysis of thermal safety (Leveneur et al., 2016). Virtual laboratories have also been applied to enhance the learning experience of existing lab-scale experiments inside the universities 
such as distillation units (Pirola, 2019) and electrolyzers (Domínguez et al., 2018) or as full virtual experience combining teaching material, simulation activities, and applicability (Rasteiro et al., 2009).

We present a different approach to deliver a real-life experience for students learning chemical reaction engineering. Through virtual experiments, students solve problems taken from real-life engineering challenges. The approach is different from the experiences described above because the real-life character is provided by the similarity between the problem statement, the actual engineering challenge and the use of industry- and research-oriented software that do not necessarily contain all the modules designed for in-class use. In this way, the students need to adjust to interfaces that are not exclusively academic-oriented. Identifying solutions to the problems through simulation analysis gives the "virtual" character to the exercise. Six reallife situations have been developed as virtual experiments and evaluated by chemical reaction engineering students. A general description is given of all virtual experiments, particularly on how they can support chemical reaction engineering courses. For one of the experiments, a detailed explanation of the theory and technical information behind it is given.

\section{Method}

Six virtual experiments were developed to introduce the students to different areas of chemical reaction engineering. While three of those situations (Experiments 1, 2 and 5) are suited for undergraduate level chemical engineering classes, the other three (Experiments 3, 4 and 6) would be of the interest of first-year graduate students and advanced undergraduate classes. 
Each experiment includes a detailed laboratory guide that states the problem and explains how to use the software to develop a solution. The problem statements are formulated such that: (i) the problems can be related to the theory discussed in class and (ii) the students are exposed to a real-life challenge of the chemical industry. Clearly some level of simplification needs to be applied to any real-life situation to be modeled. The description below clearly states such simplifications.

\subsection{Software}

The software used for the simulation and solution of the problems are $k_{\text {inetics }}{ }^{\mathrm{TM}}$ (2016) and MoDS ${ }^{\mathrm{TM}}$ (2016) developed by CMCL Innovations. $k_{\text {inetics }}{ }^{\mathrm{TM}}$ is a toolkit used to develop and apply chemical kinetic reaction models to engineering applications in the automotive, energy, and chemical processing industries (Bhave and Kraft, 2004; Bhave et al., 2006; Etheridge et al., 2011; Kraft et al., 2000; Mosbach et al., 2009; Wang et al., 2016). It comprises solutions to model homogeneous and heterogeneous chemistry in a variety of reactor models, including, perfectly and imperfectly mixed tank and plug-flow reactors, and networks of ideal reactors. It contains tools to support a variety of analysis. The Flux Analysis tool can be used to identify the most important reaction flux pathways in a chemical mechanism. The Mechanism Reduction tool can be used to reduce the complexity of large chemical mechanisms and thereby make them practical for use within multidimensional CFD simulations. The Child Case, Design of Experiments and Sensitivity Analysis tools can be used to investigate how the model responds to changes in the model parameters or process conditions. It has a graphical user interface that allows the easy set up and execution of models, 
and post processing of the simulation data. Figure 1 shows a snapshot of part of the user interface.

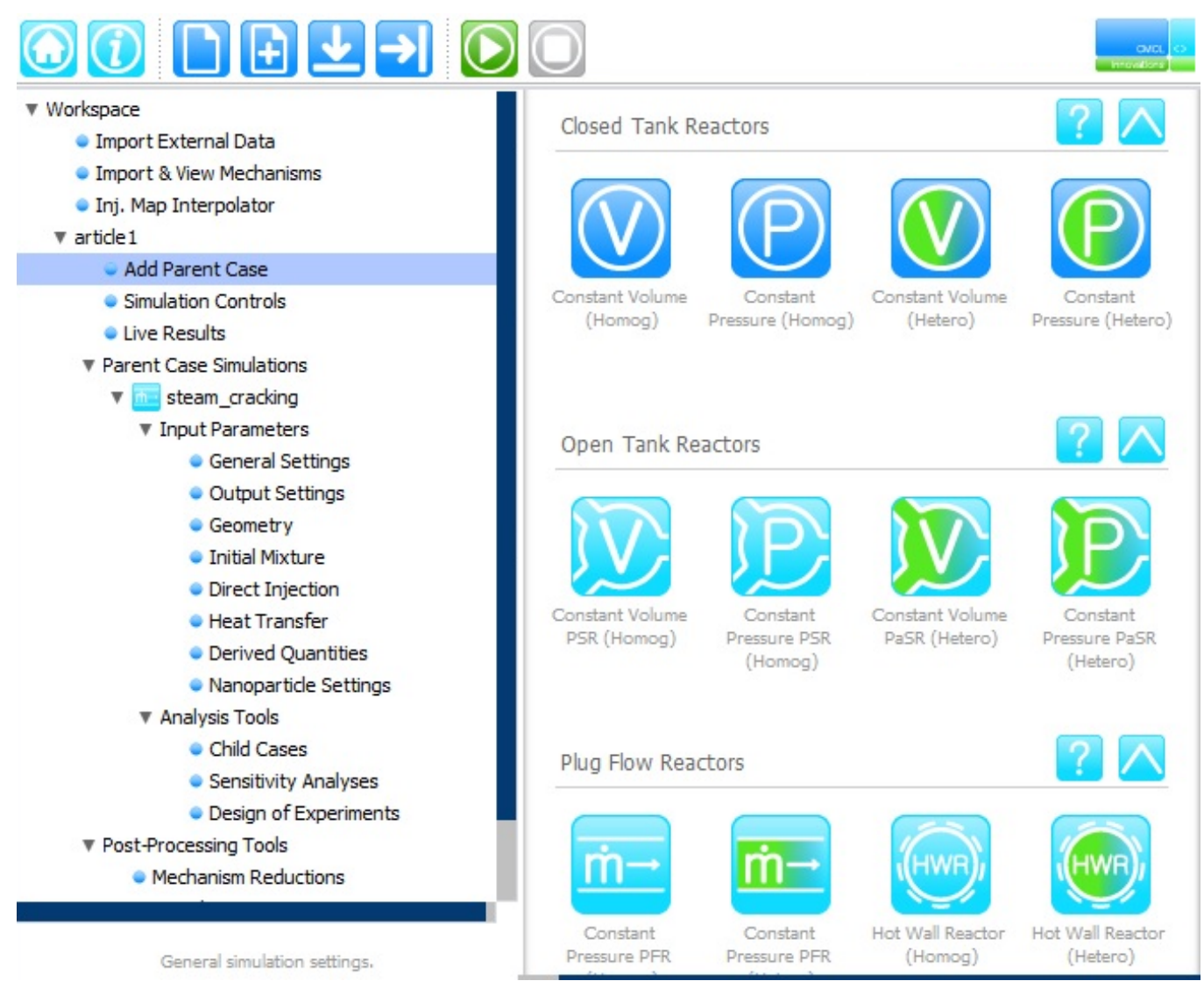

Figure 1: $k$ inetics $^{\mathrm{TM}}$ interface (2016 version).

$\operatorname{MoDS}^{\mathrm{TM}}$ (Model Development Suite) is a software tool that is designed to accelerate the process of developing computational models (Azadi et al., 2014; Bhave et al., 2017; Brownbridge et al., 2011; Mosbach et al., 2012; Smallbone et al., 2014; Taylor et al., 2013). It provides a set of advanced numerical and statistical techniques, including single- and multi-objective optimization, parameter estimation, intelligent design of experiments, data- 
driven model generation, surrogate and reduced-order model generation as well as data handling, clustering, classification and machine learning tools. Figure 2 presents a snapshot of the interface and some of the available algorithms.

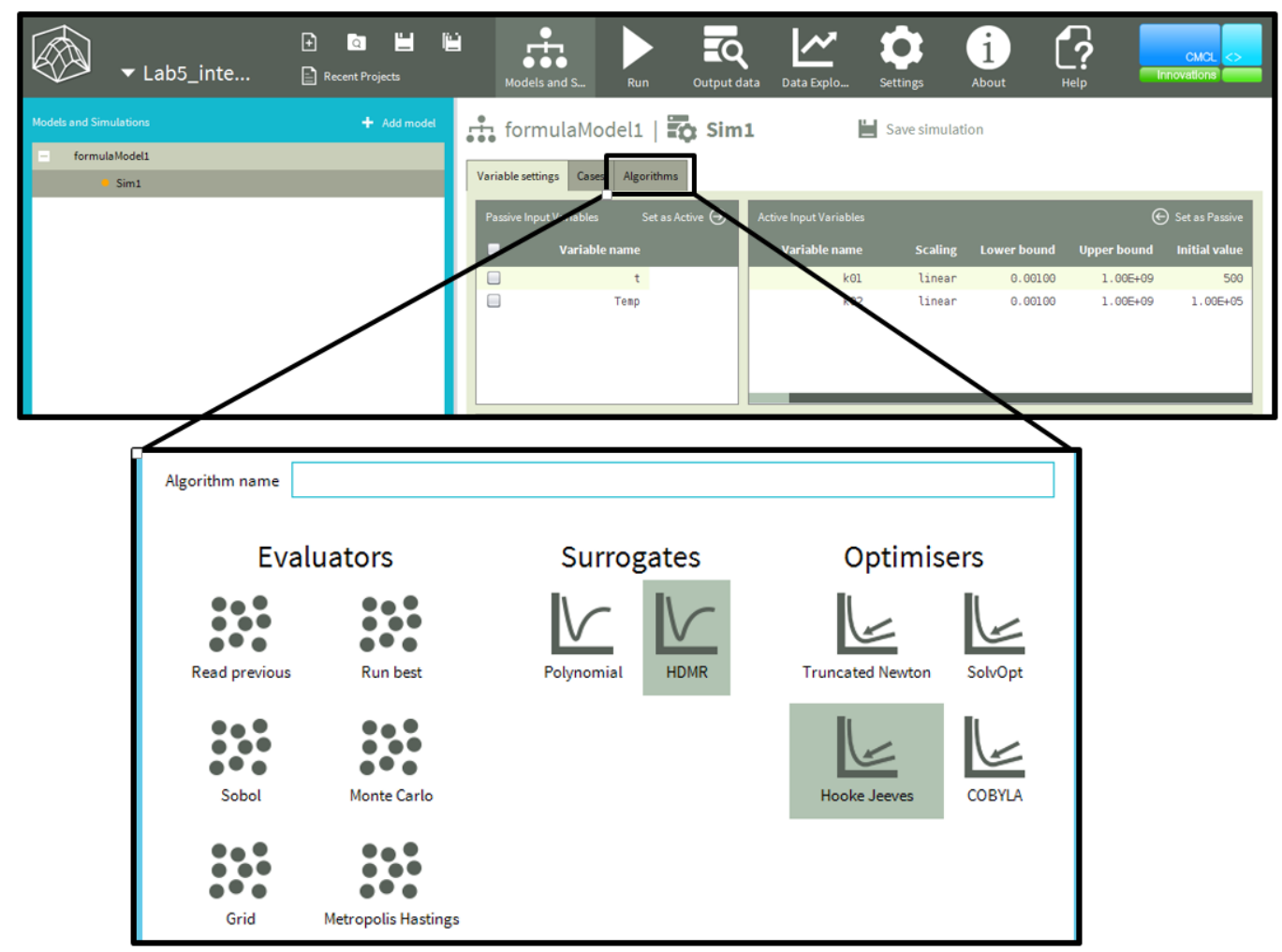

Figure 2: MoDS ${ }^{\mathrm{TM}}$ interface and available algorithms.

\subsection{Laboratory guides}

The laboratory guides for the six experiments are written in English, supplied as Supplementary Material and available online (VirtuaLab guides, 2018). Each guide states the objective of the experiment, any prerequisites (for example, the completion of tutorials related to the software), a short 
summary of the experiment, a brief background with a general description of the real-life process and relevant insights such as process details, operating conditions and kinetic data. At the end of each guide is a hyperlink to a Google form where students can complete online a report, answering questions about their understanding of the theoretical implications of each experiment. These forms are available online (VirtuaLab guides, 2018). Once students are familiar with the software they are expected to take around 4 $\mathrm{h}$ to complete each experiment. The questions are formulated to maintain and open-ended character that, to a certain extent, tries to convert the traditional student laboratory report into a project-report more similar to what engineers may write in real life.

\subsection{Implementation}

The experiments were implemented at the National University of Colombia, Medellín Campus, with students from the Chemical Engineering pro-

gram. Initially, six students that had already taken an undergraduate-level chemical reaction engineering class, carried out all six experiments in an exercise called hereinafter "the trial test", after that, a full course of 45 students performed one of the experiments as explained below, hereinafter called "full test".

\subsubsection{Trial test}

A senior group of students evaluated the laboratory guides. This stage was designed to provide feedback regarding possible issues in the operation of the industrially-oriented software and exposing students to open-ended problems that could inhibit the learning experience. This group was continually 
supported by one member from the virtual laboratory project team.

\subsubsection{Classroom implementation}

During the undergraduate chemical reaction engineering course, it was only possible to carry out one of the six exercises. Forty five students of the undergraduate class carried out Experiment 2 in Table 1. A similar evaluation of the other five experiments was not possible because of the limited availability of the students and the difficulties associated with grading virtual experiments that were still in development. The students received the guidelines for the virtual experiment after attending classes covering the appropriate theoretical background, and guidelines for installing the software on their personal computers. They had a limit of 5 days to conduct the experiment and to return the respective Google form, for which they received credit in the general grade of the course. It is noted that contrary to the software company's technical support best practices particularly for teaching applications, an on-site software demonstration and extensive training could not be performed at the University site due to the project budget constraints.

\section{Virtual experiments}

Table 1 describes the topic, the type of reactor and the area of chemical reaction engineering addressed in each virtual experiment. As it happens in real-life situations, the knowledge required to solve each individual laboratory comes from different areas of chemical reaction engineering, therefore Table 1 should be used as indicative of the knowledge that can be strengthened or supported through the use of each virtual laboratory. Particular emphasis is made in the description of Laboratory 2, as this was the only completed 
by both the smaller and larger group of students. Similar detail of the other laboratories is given as Supplementary Material. The virtual experiments intend to supplement the chemical reaction engineering course by expanding the understanding of some critical concepts. As a whole they have two main learning outcomes: (1) Increasing the understanding of a specific concept of reaction engineering by solving a real-life problem and (2) Exposure to reallife problems. The last column in Table 1 summarizes the learning outcomes expected from each virtual experiment. Those labeled with letter $(\mathrm{C})$ indicate the specific concept that the experiment addresses, those labeled with letter (E) indicate the area where the real-life problem applies. 
Table 1: General description of the six virtual experiments.

\begin{tabular}{|c|c|c|c|}
\hline Exp. & Practical process & Reactor & Learning outcomes $(*)$ \\
\hline 1 & $\begin{array}{l}\text { Ethylene steam } \\
\text { cracking }\end{array}$ & PFR & $\begin{array}{l}\text { C: Inert concentration, reactor volume, conversion } \\
\text { C: Effect of temperature on reaction rate } \\
\text { E: Refinery industry }\end{array}$ \\
\hline 2 & $\begin{array}{l}\text { Propylene steam } \\
\text { cracking }\end{array}$ & PFR & $\begin{array}{l}\text { C: Multiple reactions (Selectivity and Yield) } \\
\text { C: Economic assessment } \\
\text { E: Refinery industry }\end{array}$ \\
\hline 3 & $\begin{array}{l}\text { Diesel engine } \\
\text { performance }\end{array}$ & Batch & $\begin{array}{l}\text { C: Reactant feeding ratio } \\
\text { E: Engines, emission control, } \\
\quad \text { and Exhaust Gas Recirculation (EGR) }\end{array}$ \\
\hline 4 & $\begin{array}{c}\text { Nano-sized } \mathrm{ZnO} \\
\text { particles }\end{array}$ & $\begin{array}{l}\text { Network } \\
\text { of CSTRs }\end{array}$ & $\begin{array}{l}\text { C: Reactors in series } \\
\text { C: Reaction Quenching } \\
\text { C: Method of Moments }\end{array}$ \\
\hline 5 & $\begin{array}{c}\text { Analysis of rate data - } \\
\text { simple mechanism }\end{array}$ & Batch & $\begin{array}{l}\text { C: Parallel reactions } \\
\text { C: Parameter estimation } \\
\text { E: Combustion }\end{array}$ \\
\hline 6 & $\begin{array}{l}\text { Analysis of rate data - } \\
\text { complex mechanism }\end{array}$ & Batch & $\begin{array}{l}\text { C: Sensitivity analysis } \\
\text { E: Combustion }\end{array}$ \\
\hline
\end{tabular}

$\left.{ }^{*}\right)(\mathrm{C})$ Concept of reactor design which understanding is improved by the experiment (E) Exposure to real-life. 


\subsection{Experiment 1 - Ethylene steam cracking}

Ethylene $\left(\mathrm{C}_{2} \mathrm{H}_{4}\right)$ is one of the most important chemicals produced worldwide. It is used as a building block for a wide range of products including plastics, solvents and cosmetics. Ethylene is mostly produced in the petrochemical industry in a process, known as steam cracking, that takes place in a long tubular reactor. A typical reactor is about $80 \mathrm{~m}$ in length. The typical operating temperature is of the order of $650^{\circ} \mathrm{C}$.

Experiment 1 considers the production of ethylene from an ethane feedstock. The kinetic mechanism is simplified with a single overall reaction (R1) (Fogler, 2016). Emphasis is made on the need for steam (an inert) addition to the system to reduce the rate of secondary reactions and improve temperature control.

$$
\mathrm{C}_{2} \mathrm{H}_{6} \longrightarrow \mathrm{C}_{2} \mathrm{H}_{4}+\mathrm{H}_{2}
$$

The experiment guide highlights that coke deposition on the walls is a major drawback of these reactors. The addition of coke formation to the description of this reaction is an example of the real-life character of the problem. The guide explains that the formation of a coke layer on the walls, limits the heat transfer across the reactor walls up to a point that the external temperature of the coil, known as skin temperature, needs to be significantly increased to maintain the required heat flux to the reactor. Additional problems related to coke deposition such as a reduction in effective reactor volume and maintenance shutdowns for mandatory decoking operation are also ex-

plained. The task for the students is to devise strategies to counteract the 
negative effects of coke deposition, through the simulation of the process.

The students are asked, first, to address the effect of inert concentration, defined as a dilution factor $\left(\mathrm{kg} \mathrm{H}_{2} \mathrm{O} / \mathrm{kg}\right.$ ethane), on ethane conversion and ethylene yield. While this is clearly not an open-end question, it allows the students to gain familiarity with the reaction system.

In a second part of the experiment, the students are required to address the effect of coke formation and temperature on ethylene production. The guide explains that, while coke deposition is a transient process, one can invoke a Pseudo Steady State Hypothesis (PSSH) that considers that the gaseous phase process, i.e. R1 takes place in steady-state conditions at which the coke layer has a constant thickness and coke deposition occurs at a pseudo-constant rate. This hypothesis has reasonable validity as the rate of reaction $\mathrm{R} 1$ is orders of magnitude faster than the rate of coke deposition. In fact, a rough estimate indicates that the cross-sectional area of the reactor decreases, because of coke deposition, by $20 \%$ for every $380 \mathrm{~h}$ of operation while the residence time of the gas phase is of the order of one second. The students are asked to modify the process temperature to a value that can maintain constant ethylene production, despite the reduction in space time. This is a common problem in the industrial operation of an ethane steam cracking process, and is a powerful example to illustrate concepts such as the increase in the reaction rate as temperature increases and the effect of space time on conversion.

\subsection{Experiment 2 - Propylene steam cracking}

After the students have performed Experiment 1 and are familiarized with the simulation of the ethane steam cracking process, a change in feed- 
stock (propane) and desired product (propylene) is proposed in Experiment 2. A more complex kinetic mechanism comprising 11 reactions and 12 species (Sundaram and Froment, 1979) gives the detail required to expose the students to the analysis of selectivity and yield and how they are affected by process conditions such as inert concentration (steam dilution) and temperature.

The guide gives some background about selectivity and how to estimate the operating time before a layer of coke with a defined thickness is formed on the walls of the reactor. As well as in Experiment 1, a PSSH is also used so that a steady state solution can be obtained. This experiment gives the students the opportunity to learn that the definitions for selectivity $(\mathrm{S})$ and yield $(\mathrm{Y})$ that are traditionally presented in chemical reaction engineering courses are not universal and may present some variations depending on the reaction system in question. In the case of steam crackers, selectivity is defined as the ratio of the concentration of the desired product to that of the sum of the concentration of all hydrocarbons.

Initially the guide asks the students to explore the effect of dilution factor on propylene molar flow $\left(\mathrm{F}_{\mathrm{C}_{3} \mathrm{H}_{6}}\right)$, selectivity $\left(\mathrm{S}_{\mathrm{C}_{3} \mathrm{H}_{6}}\right)$ and yield $\left(\mathrm{Y}_{\mathrm{C}_{3} \mathrm{H}_{6}}\right)$. This is an open-ended question that requires the students to propose a value of the dilution factor at which to operate the steam cracker. Interestingly, the students will find that the curves of $\mathrm{F}_{\mathrm{C}_{3} \mathrm{H}_{6}}, \mathrm{~S}_{\mathrm{C}_{3} \mathrm{H}_{6}}$ and $\mathrm{Y}_{\mathrm{C}_{3} \mathrm{H}_{6}}$ do not show any maximum with dilution factor, as shown in Figure 3, which leaves them with a sense of uncertainty and unease that are resolved in the last section of the guide.

The students are also asked to explore the effect of temperature on $\mathrm{F}_{\mathrm{C}_{3} \mathrm{H}_{6}}$, 

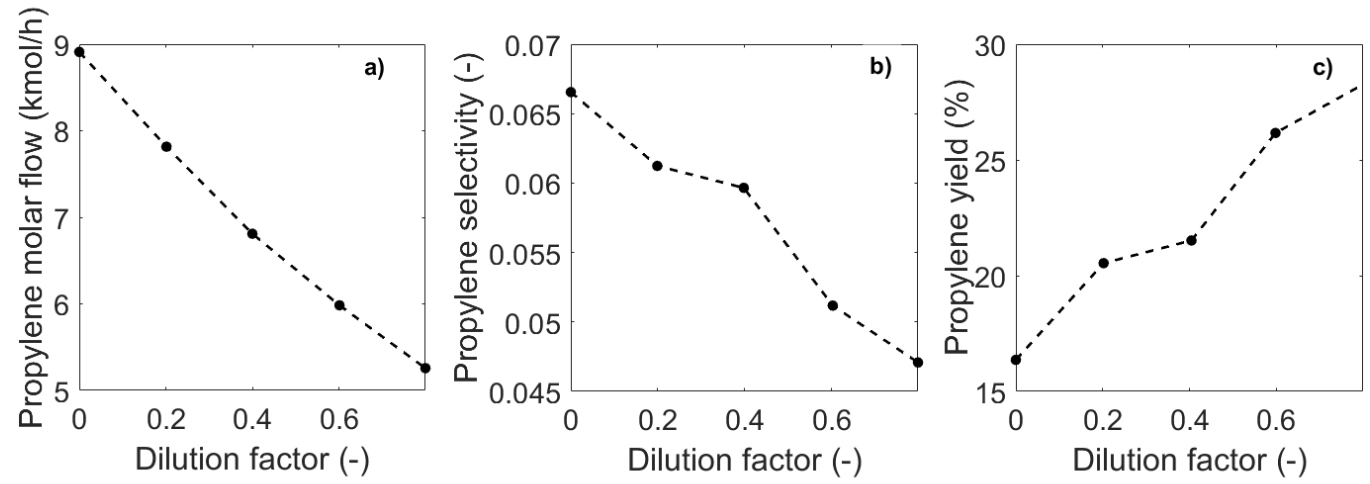

Figure 3: Results expected for Experiment 2. Effect of dilution factor on different metrics related to the production of propylene during the hydrocracking of propane. a) Molar flow, b) Selectivity and c) Yield.

$\mathrm{S}_{\mathrm{C}_{3} \mathrm{H}_{6}}$ and $\mathrm{Y}_{\mathrm{C}_{3} \mathrm{H}_{6}}$. Figure 4 shows the expected variation of propylene molar flow (Figure 4a), selectivity (Figure 4b), and yield (Figure 4c) with temperature. As was the case with the dilution factor, no unique temperature renders a maximum for the three variables.

A higher temperature not only yields a higher propylene molar flow (Figure 4a) but also favors coke formation, as evidenced in Figure 5a that presents the variation of the rate of coke formation with temperature. A higher dilution factor, on the contrary decreases propylene molar flow and selectivity, but is beneficial from the point of view of coke formation control, decreasing its production rate, as illustrated in Figure 5b.

To give the students an additional tool to balance the positive and negative effects of the design variables, the guide introduces a simplified version of the economic analysis of a steam cracker discussed in Berreni and Wang 

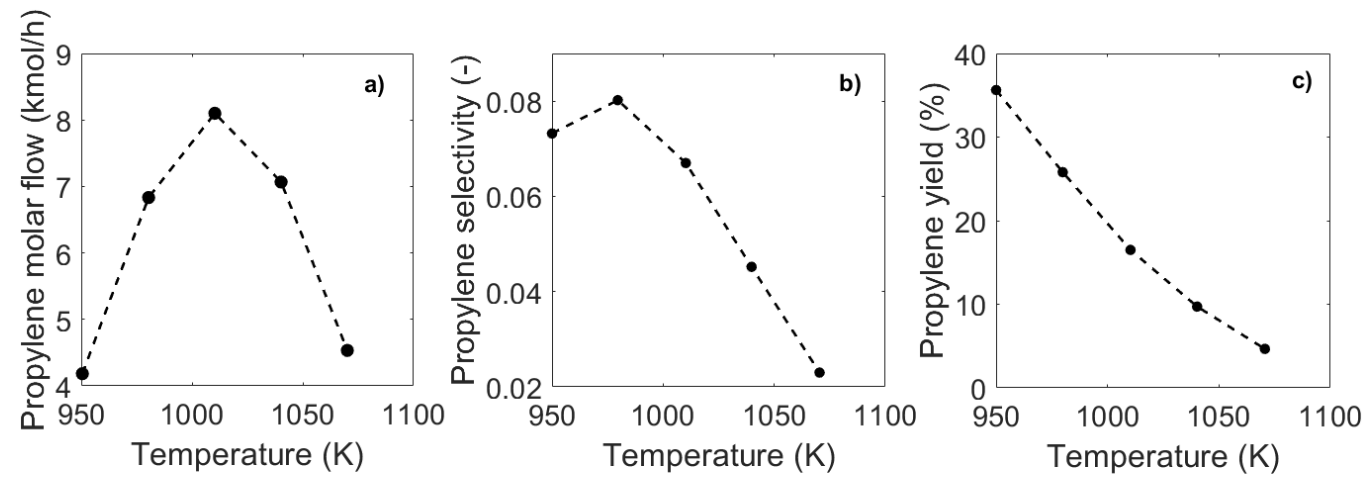

Figure 4: Results expected for Experiment 2. Effect of temperature on different metrics related to the production of propylene during the hydrocracking of propane. a) Molar flow, b) Selectivity and c) yield.

(2011). The students are requested to determine the combination of temperature and dilution factor that guarantees the best profit at a condition of significant propylene production, but with a low number of decoking operations. They estimate this by computing the annual operating profit $(P)$ using Equation 1 for each point from a factorial experimental design covering three levels for two design variables: dilution factor and process temperature.

$$
\begin{array}{r}
P(\$)=\left(F_{C_{3} H_{6}} C_{C_{3} H_{6}}\right) n t_{0}+\left(F_{C_{2} H_{4}} C_{C_{2} H_{4}}\right) n t_{0}-\left(F_{C_{3} H_{8}} C_{C_{3} H_{8}}\right) n t_{0} \\
-\left(F_{H_{2} O} C_{H_{2} O}\right) n t_{0}-n D C C
\end{array}
$$

where $C_{3} H_{6}$ and $C_{2} H_{4}$ are the valuable products when operating the cracker for a continuous period of $t_{0}$ hours, with $n$ decoking operations in a year, with the losses associated to the cost of $\mathrm{C}_{3} \mathrm{H}_{8}$ and $\mathrm{H}_{2} \mathrm{O}$ and of a 

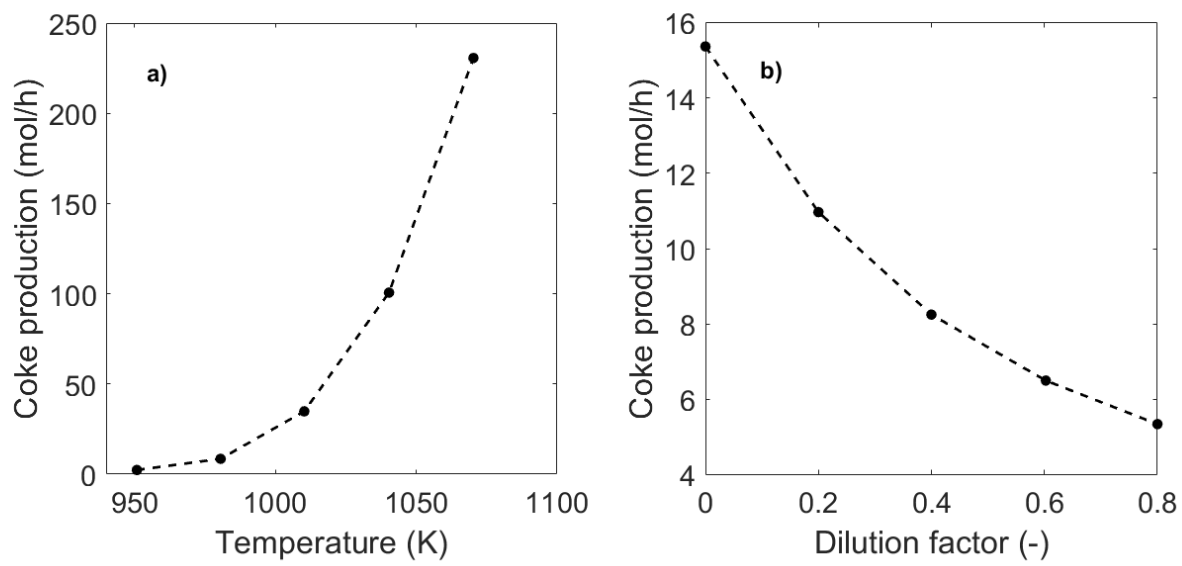

Figure 5: Results expected for Experiment 2. Coke production rate as function of operating variables during the production of propylene via the hydrocracking of propane. a) Effect of temperature b) Effect of dilution factor.

decoking operation $(D C C) . F_{\mathrm{i}}$ and $C_{\mathrm{i}}$ represent the mass flow and the cost of species i, respectively.

\subsection{Experiment 3-Diesel engine performance}

Chemical reaction engineering can explain real-life processes far beyond the chemical industry sector. This experiment was specifically designed to illustrate this feature of reaction engineering to students in the context of emissions control technologies in modern diesel fuelled compression ignition engines. The experiment is introduced with a short description of internal combustion engines. Concepts such as engine efficiency, nitrogen oxide formation and its regulation for vehicle emissions, fuel-air equivalence ratio $(\phi$, a term frequently used in the automobile community that defines the quantity of fuel in a fuel-air mixture; the equivalence ratio is the ratio of the 
actual fuel/air ratio to the stoichiometric fuel/air ratio), and exhaust gas recirculation (EGR) are explained to provide the students with the background knowledge required to solve the problem. The reactor models in $k$ inetics ${ }^{\mathrm{TM}}$ (and its sister product the SRM Engine Suite, which comes with a number of built-in reactor models to simulate different types of reciprocating engine) are particularly suited for the analysis of automobile-related problems and come with the ability to directly specify mixtures in terms of $\phi$. This experiment takes advantage of the fact that $k_{\text {inetics }}{ }^{\mathrm{TM}}$ comes with a library of reaction mechanism for different engine applications, including a detailed kinetics for diesel combustion.

The students are requested to compute the space time of a four-stroke engine. While the calculation is straightforward, the conversion of the engine speed and fuel and air flow to space time demands the ability to translate basic classroom concepts to the real engine. Similar skills are fostered by representing the fuel as iso-octane for stoichiometric purposes and by the need to translate the software results (e.g. $\mathrm{NO}_{x}$ exhaust concentration) to relevant engineering values (e.g. $\mathrm{NO}_{x}$ emissions in $\mathrm{g} / \mathrm{km}$ ). To perform the simulation in inetics $^{\mathrm{TM}}$, students are asked to treat the engine as a constant volume adiabatic batch reactor. This is clearly an approximation that is reasonable in the sense that in a four-stroke engine the combustion is very fast compared to the velocity at which the piston moves, and heat is transferred outside the cylinder wall. Therefore, constant volume and adiabatic conditions may be assumed.

In a first activity the students find that there is a value of $\phi$ that yields a maximum in combustion performance by computing an Efficiency Indicator 
(EI) for different $\phi$ values. The students also find that at this value of $\phi$, $\mathrm{NO}_{x}$ emissions are below the $\mathrm{NO}_{x}$ emission standard.

In a second activity the students repeat the calculation when $\phi$ is higher than the value found in the first activity. At this value the $\mathrm{NO}_{x}$ emissions are above the emission standard. This exercise highlights the important relation between $\phi$ and $\mathrm{NO}_{x}$ emissions. In a final activity, students add Exhaust Gas Recirculation (EGR) to the system. This is easily carried out in $k$ inetics ${ }^{\mathrm{TM}}$ as EGR is an input option when modeling constant-volume, adiabatic reactors. From these results, the students are asked about the use of EGR as a level to control the $\mathrm{NO}_{x}$ emissions in Diesel engine.

\subsection{Experiment 4-Nano-sized $\mathrm{ZnO}$ particles}

Experiment 4 discusses the synthesis of $\mathrm{ZnO}$ nanoparticles using a modelling approach that includes two main stages: (i) the evaporation at 2500 $\mathrm{K}$ of coarse-sized and low-value $\mathrm{ZnO}$ particles and the subsequent reduction with $\mathrm{CH}_{4}$ to obtain $\mathrm{Zn}$ vapor and (ii) the use of a controlled amount of ambient air to oxidize $\mathrm{Zn}_{\text {(vapor) }}$, to form $\mathrm{ZnO}$ nanoparticles.

Given the importance of nanotechnology in current engineering developments, this exercise is aimed at motivating students to learn about some of the challenges related to this technology. It introduces the use of the method of moments to describe the size distribution of the nanoparticles. In the background section the students are provided with information to familiarize them with particle processes such as nucleation, coagulation, and particle depletion. $k$ inetics $^{\mathrm{TM}}$ includes a choice of computational methods that describe the particles in different levels of detail (and hence complexity) to simulate the evolution of a particulate phase interacting with a continuous 
(gas) phase. The method of moments used in this exercise is one of the simplest approaches for solving particle population balance equations and considers only the most important physicochemical processes affecting the particles. While the mathematics behind the method of moments may be beyond the scope of a reaction engineering class, the phenomena associated with nanoparticle formation is closely related to many of the concepts that are taught in chemical reaction engineering. Furthermore, chemical engineering graduates would be expected to use computational tools similar to $k_{\text {inetics }}{ }^{\mathrm{TM}}$ if working with particulate processes. Their understanding of the phenomena behind this software is, therefore, of key importance in engineering classes.

The reaction and quenching stages typical in this process, are modeled as the combination of two reactors in series. The oxidation of zinc vapours and preliminary particle growth take place in the first reactor, referenced in the guide as Oxidation Reactor, and the final growth and quenching in the second reactor (Quench Reactor). The students need to build the reactor network using inetics $^{\mathrm{TM}}$ interface. As outputs, the software calculates the total number of particles, temperature and average particle diameter as a function of time for both reactors. The guide challenges the students to propose values for i) the volume of the Quench Reactor and ii) the cooling air flow rate for the Oxidation Reactor such that the particle diameter is between 10 and $15 \mathrm{~nm}$ at the outlet from the Oxidation Reactor and no bigger than $18 \mathrm{~nm}$ at the outlet from the Quench Reactor. In order to do this, the students need to perform a set of simulations to evaluate the effect of the above design variables on the process performance. 


\subsection{Experiments 5 and 6 - Data analysis of reaction data}

Experiments 5 and 6 seek to teach students about modern methods to analyze complex reaction systems, over an about what would be possible using the graphical methods described in early chemical reaction engineering books. However, the success of data analysis with current algorithms strongly depends on the correct understanding of the problem.

Experiment 5 combines the traditional integral method for the analysis of rate data with the algorithms available in $\mathrm{MoDS}^{\mathrm{TM}}$. The aim is to estimate rate parameters for key intermediate reactions in a chemical mechanism describing the combustion of $\mathrm{H}_{2}$. This combustion process has been chosen as an example of clean energy generation. The problem considers a branch of the $\mathrm{H}_{2} / \mathrm{O}_{2}$ mechanism that is highly relevant at high pressure (10-30 atm) and relatively low temperature (less than $1800 \mathrm{~K}$ ) in order to reduce $\mathrm{NO}_{\mathrm{x}}$ emissions (Burke et al., 2011; Mueller et al., 1999). The input data presents the typical uncertainty of real experiments adding more real-life features to the experiment.

The chemical mechanism for the $\mathrm{H}_{2}$ combustion considers $\mathrm{HO}_{2}, \mathrm{H}$ and $\mathrm{OH}$ as key intermediates as shown in elementary reactions R2 and R3. Equation 2 showed the expression used tp calculate the rate of each reaction.

$$
\begin{array}{cc}
\mathrm{HO}_{2}+\mathrm{H} \longrightarrow \mathrm{H}_{2}+\mathrm{O}_{2} & \mathrm{R} 2 \\
\mathrm{HO}_{2}+\mathrm{H} \longrightarrow \mathrm{OH}+\mathrm{OH} & \mathrm{R} 3 \\
r_{i}=A_{0, i} T^{n_{i}} e^{-E_{a, i} / R T} \prod_{j=1}^{N_{s}} c_{j}^{\alpha_{j}} & \text { (2) }
\end{array}
$$


where $\mathrm{A}_{0, i}$ is the pre-exponential factor of reaction $i, \mathrm{n}_{\mathrm{i}}$ is the exponent of temperature that is particularly important for reactions taking place at low temperatures, $\mathrm{E}_{\mathrm{a}, i}$ is the activation energy for reaction $i, N_{\mathrm{s}}$ is the total number of species, $c_{j}$ is the molar concentration of species $j$ in the system and $\alpha_{j}$ an exponent that, for an elementary reaction, corresponds to the stoichiometric coefficient.

The values of $\mathrm{n}_{i}$ and $\mathrm{E}_{\mathrm{a}, i}$ are given to the students. The unknowns are the pre-exponential constants, $\mathrm{A}_{0, i}$, for both reactions. While the fitting procedure seems straightforward because there is enough experimental data and there are only two parameters to determine, there is one caveat, the data is obtained at two very different temperature values. The students are challenged with the task of finding the best values to fit experimental data at both low and high temperatures.

The students should first derive an algebraic expression to compute the $\mathrm{HO}_{2}$ concentration as a function of time, temperature, initial concentration of $\mathrm{HO}_{2}$ and $\mathrm{H}$ and the kinetics parameters for reactions $\mathrm{R} 2$ and $\mathrm{R} 3$. Using this expression and making use of the fitting algorithms available in $\mathrm{MoDS}^{\mathrm{TM}}$, the students should perform a first round of fitting using the low-temperature experimental data and verify that the resulting parameters yield acceptable predictions for the low temperature regimes but that, particularly at high temperatures, experimental data is significantly underestimated. The inclusion of the high-temperature experimental data in a second round of fitting not only significantly improves the predictions at high temperature but uncovers the fact that, while only one of the reactions is relevant at low temperatures, both reactions have a significant effect in the concentration profile 
at high temperatures. This two-reaction system is an example of a chemical mechanism that displays an apparent temperature-dependent activation energy.

Experiment 6 expands on the $\mathrm{H}_{2}$ combustion problem. The guide explains that in some cases a simple reaction mechanism, for example that described by reactions $\mathrm{R} 2$ and $\mathrm{R} 3$, is not enough to properly capture the chemistry of a system. While in Experiment 5 reactions R2 and R3 were sufficient to predict the species concentrations, more complex quantities, in this case the ignition delay time, require a more detailed mechanism. The guide presents a alternative mechanism of 13 species and 27 reactions, and provides a datafile containing the associated kinetic and thermodynamic data than can be easily imported into inetics $^{\mathrm{TM}}$ and $\mathrm{MoDS}^{\mathrm{TM}}$.

Experiment 6 illustrates that the use of a detailed chemical reaction mechanism introduces the technical challenge of handling a large number of parameters, which makes mechanism calibration difficult. To alleviate the difficulties of having numerous parameters, the guide introduces the concept of sensitivity analysis. The experiment encourages the students to perform a sensitivity analysis to identify the chemical reactions with the largest effect on ignition delay time. The supplied version of the chemical mechanism overestimates the ignition delay time and the laboratory guide remarks that fitting the mechanism by optimizing the full set of kinetic parameters for all 27 reactions is difficult. However, if the optimization problem is limited to the kinetic parameters with the highest sensitivity coefficients, the optimization problem is significantly simplified. The students are required to use $\mathrm{MoDS}^{\mathrm{TM}}$ to perform this optimization. The resulting fitted mechanism 
shows much better agreement with experimental data.

\section{Result and analysis}

The senior group of students was instrumental in finalizing the design of the experiments. A major concern in Experiment 1 was the fact that while the guide described a clear real-life situation, there were too many assumptions in the approach suggested to solve the problem. The students wanted to add more complexity to the problem in order to reduce the number of assumptions. The fact that the energy equation is not coupled to the solution and that the coke deposit uniformly builds along the reactor particularly worried this senior group. As Experiment 1 was designed as a first exposure to residence time and dilution, this difficulty should be less evident in an actual undergraduate class.

In Experiment 2 the senior group experienced the expected sense of unease given the absence of an optimal dilution factor without adding the additional economic considerations to the problem. This economic analysis was considered a very positive part of Experiment 2 and is not often included in traditional chemical engineering books. Experiment 3 introduces a number of engine-related concepts that made the experiment challenging for the senior group. However, they were strongly motivated by the context of understanding $\mathrm{NO}_{x}$ emissions control technology using exhaust gas recirculation in a diesel engine.

The application of reaction engineering to state-of-the-art areas, such as the production of nanopowders described in Experiment 4, was regarded as very motivating by the students. The possibility of using software to predict 
nanoparticle growth without getting into the complex mathematics associated with the method of moments was received very positively. This is in contrast to most examples in chemical reaction engineering typically demand prior mastery of the mathematics before solving the engineering problem. Experiment 4, in that sense, faces the students with a rather common practice in engineering. Sophisticated software is used to solve an engineering problem, where the emphasis is on finding the best solution rather than on how the solution is obtained. This is consistent with other areas, where, for example, current advances in artificial intelligence are considered as drivers for scenarios where engineers will be responsible for setting up the problem, machines will solve any required mathematics and provide possible solutions, and engineers would select the best solution (Frey and Osborne, 2013).

As experiments 5 and 6 challenge the students to find rate parameters for more than one reaction. The senior group viewed these experiments as a logical advance from the more traditional problems used to introduce the topic of rate parameter estimation. Given that the students were already familiar with parameter fitting algorithms, it was rather simple to fit the rate parameter for a single reaction. Nevertheless, students considered that the real-life character of both experiments, particularly of Experiment 6, to be confusing because both problems seemed to be more related to a research laboratory than to a practical engineering use case.

A full test of experiment 2 was performed using a full class of $45 \mathrm{stu}-$ dents from the undergraduate programme. While the students described the experiment as similar to their expectations of real engineering, there were a number of practical issues that caused significant frustration among students 
and obscured the evaluation. For example, the number and frequency of requests to the licence server caused problems with checking out licences. This was fed back to the software vendors, who have since changed the licence handling to solve this issue. Further, the fact that the students could not access extended online support as is possible for widely-used software packages such as Matlab influenced their final evaluation. However, we regarded this as a positive unforeseen result as real-life engineering practice often comes with unexpected challenges. Problems with software licenses and the lack of freely available tutorial videos via Google are merely examples of this. Nevertheless, in order that the solution of the real-life engineering challenge is in the foreground of the virtual experiment, it is the task of the Experiment superviser to minimize any kind of software-related problem.

Another challenge commonly encountered when trying to use state-ofthe-art industrial software and/or hardware are the associated additional financial and time costs (Botero et al., 2016). This continues to be the case even after generous discounting and support of the software (as was the case here), and requires the close collaboration and sustained effort of the academic and industrial partners to implement this type of methodology in the education of engineers.

\section{Conclusions}

A virtual laboratory that uses industrial software to solve real-life chemical engineering problems was developed to support the teaching of chemical reaction engineering. Six experiments were developed, and were tested by undergraduate students taking the chemical reaction engineering course at 
the National University of Colombia.

The experiments introduce problems based on real-life engineering situations including steam cracking, diesel and $\mathrm{H}_{2}$ combustion and nanoparticle synthesis. The experiments give students the opportunity to apply chemical engineering concepts to real-life engineering challenges, and in this way support their understanding of chemical reaction engineering.

The inclusion of open-ended problems with no single correct answer was observed to cause some initial frustration amongst the students. However, the subsequent demonstration of how such problems can be closed by introducing additional constraints, for example economic or environmental considerations, was met with very positive feedback. The overall approach was supported by the students.

The introduction of industrial software into the reaction engineering course imposed several challenges and opportunities. Such computational tools are not necessarily classroom-oriented, and the students experienced a few difficulties in starting to work with them. However, once students understood how to use the software they found the ability to solve real-life problems very motivating. Furthermore, the lack of internet-available answers to solve software-operating problems forced students to find their own solutions, adding to the real-life character of the experiments.

\section{Acknowledgement}

This research was funded by the Royal Academy of Engineering under its Industry Academia Partnership Programme with reference IAPP $\backslash 1516 \backslash 107$ : VirtuaLab "Development of a Virtual Laboratory for teaching in Chemical 
Engineering using industrial-standard software".

\section{References}

\section{References}

Ancheyta, J., 2017. Chemical Reaction Kinetics: Concepts, Methods and Case Studies. John Wiley \& Sons.

Aris, R., 1999. Elementary Chemical Reactor Analysis. Courier Corporation.

Azadi, P., Brownbridge, G., Mosbach, S., Smallbone, A., Bhave, A., Inderwildi, O., Kraft, M., 2014. The carbon footprint and non-renewable energy demand of algae-derived biodiesel. Applied Energy 113, 16321644. URL: http://www.sciencedirect.com/science/article/pii/ S0306261913007745, doi:https://doi.org/10.1016/j . apenergy . 2013. 09.027.

Berreni, M., Wang, M., 2011. Modelling and dynamic optimisation for optimal operation of industrial tubular reactor for propane cracking, in: Pistikopoulos, E., Georgiadis, M., Kokossis, A. (Eds.), 21 European Symposium on Computer Aided Process Engineering. Elsevier. volume 29, pp. 955-959. URL: http://www.sciencedirect.com/science/ article/pii/B9780444537119501917, doi:https://doi.org/10.1016/ B978-0-444-53711-9.50191-7.

Bhave, A., Kraft, M., 2004. Partially Stirred Reactor Model: Analytical Solutions and Numerical Convergence Study of a PDF/Monte 
Carlo Method. Siam Journal on Scientific Computing 25. doi:10.1137/ S1064827502411328.

Bhave, A., Kraft, M., Montorsi, L., Mauss, F., 2006. Sources of $\mathrm{CO}$ emissions in an HCCI engine: A numerical analysis. Combustion and Flame 144, 634-637. URL: http://www.sciencedirect. com/science/article/pii/S0010218005003263, doi:https://doi.org/ $10.1016 / j$. combustflame.2005.10.015.

Bhave, A., Taylor, R.H.S., Fennell, P., Livingston, W.R., Shah, N., Dowell, N.M., Dennis, J., Kraft, M., Pourkashanian, M., Insa, M., Jones, J., Burdett, N., Bauen, A., Beal, C., Smallbone, A., Akroyd, J., 2017. Screening and techno-economic assessment of biomass-based power generation with CCS technologies to meet 2050 CO2 targets. Applied Energy 190, 481489. URL: http://www.sciencedirect.com/science/article/pii/ S0306261916319043, doi:https://doi .org/10.1016/j . apenergy . 2016. 12.120 .

Botero, M.L., Selmer, A., Watson, R., Bansal, M., Kraft, M., 2016. Cambridge Weblabs: A process control system using industrial standard SIMATIC PCS 7. Education for Chemical Engineers 16, 1-8. URL: http://www.sciencedirect.com/science/article/pii/ S1749772816300070.

Brownbridge, G.P.E., Smallbone, A., Phadungsukanan, W., Mosbach, S., Kraft, M., Johansson, B., 2011. Automated IC Engine Model Development with Uncertainty Propagation. doi:https://doi .org/10.4271/2011-010237. 
Burke, M.P., Chaos, M., Ju, Y., Dryer, F.L., Klippenstein, S.J., 2011. Comprehensive $\mathrm{H} 2 / \mathrm{O} 2$ kinetic model for high-pressure combustion. Int. J. Chem. Kinet. 44, 444-474.

Chen, W., Shah, U., Brechtelsbauer, C., 2016. The discovery laboratory - A student-centred experiential learning practical: Part I - Overview. Educ. Chem. Eng. 17, 44-53.

Davis, M.E., Davis, R.J., 2013. Fundamentals of Chemical Reaction Engineering. Courier Corporation.

Domínguez, J.C., Miranda, R., González, E.J., Oliet, M., Alonso, M.V., 2018. A virtual lab as a complement to traditional hands-on labs: Characterization of an alkaline electrolyzer for hydrogen production. Education for Chemical Engineers, 1-10URL: https://doi.org/10.1016/j.ece. 2018.03.002, doi:10.1016/j.ece.2018.03.002.

Doraiswamy, L.K., Uner, D., 2013. Chemical Reaction Engineering: Beyond the Fundamentals. CRC Press.

Etheridge, J., Mosbach, S., Kraft, M., Wu, H., Collings, N., 2011. Modelling soot formation in a DISI engine. Proceedings of the Combustion Institute 33, 3159-3167. URL: http://www.sciencedirect. com/science/article/pii/S1540748910003020, doi:https://doi.org/ 10.1016/j.proci.2010.07.039.

Fogler, H.S., 2016. Elements of Chemical Reaction Engineering. Prentice Hall. 
Fogler, H.S., Gurmen, M.N., 2019. Chemical Reaction Engineering: Fogler \& Gurmen. URL: http://www.umich.edu/ essen/. accessed: 2018-4-5.

Frey, C.B., Osborne, M.A., 2013. The future of employment: how susceptible are jobs to computerisation? URL: https://www.oxfordmartin.ox.ac . uk/downloads/academic/The_Future_of_Employment.pdf.

Froment, G.F., Bischoff, K.B., De Wilde, J., 2010. Chemical Reactor Analysis and Design, 3rd Edition. John Wiley \& Sons, Incorporated.

Froment, G.F., Bischoff, K.B., De Wilde, J., 2019. Chemical reactor analysis and design, 3rd edition - instructor companion site. URL: http://bcs.wiley.com/he-bcs/Books?action=index\& itemId $=0470565411 \& b \operatorname{cs} I d=5864$.

Holland, C.D., Anthony, R.G., 1979. Fundamentals of chemical reaction engineering. Prentice-Hall.

kinetics \& SRM Engine Suite software, 2016. CMCL innovations. UK.

Koretsky, M.D., Amatore, D., Barnes, C., Kimura, S., 2008. Enhancement of Student Learning in Experimental Design Using a Virtual Laboratory. IEEE Trans. Educ. 51, 76-85.

Kraft, M., Maigaard, P., Mauss, F., Christensen, M., Johansson, B., 2000. Investigation of combustion emissions in a homogeneous charge compression injection engine: Measurements and a new computational model. Proceedings of the Combustion Institute 28, 1195-1201. URL: http://www.sciencedirect.com/ 
science/article/pii/S0082078400803306, doi:https://doi.org/10. 1016/S0082-0784(00)80330-6.

Kramers, H., Westerterp, K.R., 1963. Elements of Chemical Reactor Design and Operation. Academic Press Inc.

Leveneur, S., Vernieres-Hassimi, L., Salmi, T., 2016. "mass \& energy balances coupling in chemical reactors for a better understanding of thermal safety". Education for Chemical Engineers 16, 17 - 28. URL: http://www.sciencedirect.com/science/article/ pii/S1749772816300045, doi:https://doi.org/10.1016/j.ece.2016. 06.002.

Levenspiel, O., 1962. Chemical Reaction Engineering. An introduction to the design of chemical reactors. John Wiley and Sons Inc.

Levenspiel, O., 1999. Chemical reaction engineering. John Wiley \& Sons Inc.

Levenspiel, O., 2019. Levenspiel: Chemical Reaction Engineering, 3rd Edition - Instructor Companion Site. URL: http://bcs.wiley.com/he-bcs/ Books?action $=$ index\&itemId $=047125424$ X\&bcs $I d=3002$.

Li, S., Xin, F., Li, L., 2017. Reaction Engineering. Butterworth-Heinemann, Boston. URL: https://www. sciencedirect.com/book/9780124104167/ reaction-engineering.

Marin, G.B., Yablonsky, G.S., 2011. Kinetics of Chemical Reactions: Decoding Complexity. John Wiley \& Sons. 
Missen, R.W., Missen, R.W., Mims, C.A., Saville, B.A., 1999. Introduction to chemical reaction engineering and kinetics. John Wiley and Sons Inc.

Model Development Suite (MoDS), 2016. CMCL innovations. UK.

Molderez, I., Fonseca, E., 2018. The efficacy of real-world experiences and service learning for fostering competences for sustainable development in higher education. J. Clean. Prod. 172, 4397-4410.

Mosbach, S., Braumann, A., Man, P.L.W., Kastner, C.A., Brownbridge, G.P.E., Kraft, M., 2012. Iterative improvement of Bayesian parameter estimates for an engine model by means of experimental design. Combustion and Flame 159, 1303-1313. URL: http://www. sciencedirect. com/science/article/pii/S0010218011003245, doi:https://doi.org/ $10.1016 / j$. combustflame.2011.10.019.

Mosbach, S., Celnik, M.S., Raj, A., Kraft, M., Zhang, H.R., Kubo, S., Kim, K.O., 2009. Towards a detailed soot model for internal combustion engines. Combustion and Flame 156, 11561165. URL: http://www.sciencedirect.com/science/article/pii/ S0010218009000054, doi:https://doi.org/10.1016/j.combustflame. 2009.01 .003$.

Mueller, M.A., Kim, T.J., Yetter, R.A., Dryer, F.L., 1999. Flow reactor studies and kinetic modeling of the $\mathrm{H} 2 / \mathrm{O} 2$ reaction. Int. J. Chem. Kinet. $31,113-125$.

Naukkarinen, J., Sainio, T., 2018. Supporting student learning of chemical 
reaction engineering using a socially scaffolded virtual laboratory concept. Educ. Chem. Eng. 22, 61-68.

Pirola, C., 2019. Education for Chemical Engineers Learning distillation by a combined experimental and simulation approach in a three steps laboratory : Vapor pressure, vapor-liquid equilibria and distillation column. Education for Chemical Engineers 28, 54-65. URL: https://doi.org/ 10.1016/j.ece.2019.05.003, doi:10.1016/j.ece.2019.05.003.

Ranade, V.V., 2002. Computational Flow Modeling for Chemical Reactor Engineering. Academic Press.

Rasteiro, M.G., Ferreira, L., Teixeira, J., Bernardo, F.P., Carvalho, M.G., Ferreira, A., Ferreira, R.Q., Garcia, F., Oliveira, N., Quina, M., Santos, L., Saraiva, P.A., Mendes, A., Almeida, A.S., Granjo, J., Ascenso, M., Bastos, R.M., Borges, R., 2009. LABVIRTUAL - A virtual platform to teach chemical processes 4, 9-19. doi:10.1016/j.ece.2009.02.001.

Schmal, M., 2014. Chemical Reaction Engineering: Essentials, Exercises and Examples. CRC Press.

Schmidt, L.D., 2009. The Engineering of Chemical Reactions. Oxford University Press.

Smallbone, A., Bhave, A., Man, P., 2014. High-Dimensional Sensitivity Analysis Applied at Vehicle Component and System Level in the Context of CO2 Exhaust Emissions. doi:https ://doi .org/10.4271/2014-01-2564.

Sundaram, K.M., Froment, G.F., 1979. Kinetics of coke deposition in the thermal cracking of propane. Chem. Eng. Sci. 34, 635-644. 
Taylor, B., Xiao, N., Sikorski, J., Yong, M., Harris, T., Helme, T., Smallbone, A., Bhave, A., Kraft, M., 2013. Techno-economic assessment of carbonnegative algal biodiesel for transport solutions. Applied Energy 106, 262274. URL: http://www.sciencedirect.com/science/article/pii/ S0306261913000767, doi:https://doi .org/10.1016/j . apenergy . 2013. 01.065 .

Trambouze, P., Euzen, J.P., 2007. Chemical Reactors. Editions OPHRYS.

VirtuaLab guides, 2018. Bioprocess and Reactive Flows. URL: https://minas .medellin. unal.edu.co/gruposdeinvestigacion/ biofrun/resources2/virtualab-lab-guides.html. accessed: 2019-115.

Walas, S.M., 2013. Reaction Kinetics for Chemical Engineers: Butterworths Series in Chemical Engineering. Butterworth-Heinemann.

Wang, B., Mosbach, S., Schmutzhard, S., Shuai, S., Huang, Y., Kraft, M., 2016. Modelling soot formation from wall films in a gasoline direct injection engine using a detailed population balance model. Applied Energy 163, 154-166. URL: http://www.sciencedirect.com/ science/article/pii/S030626191501452X, doi:https://doi.org/10. 1016/j . apenergy . 2015.11.011.

Wolff, K.E., Dorfling, C., Akdogan, G., 2018. Shifting disciplinary perspectives and perceptions of chemical engineering work in the 21st century. Educ. Chem. Eng. 24, 43-51. 


\section{References}

